\title{
Resumo das linhas de pesquisas
}

FRANCISCO GORGÓNIO NÓBREGA

- Departamento de Biologia:

O Departamento realiza pesquisas em biologia molecular e celular, genética e citogenética e genética das populaçóes e evolução em vários sistemas biológicos: fungos, bactérias, platelmintos, moluscos, insetos, peixes, répteis, aves e mamíferos, incluindo o homem. Os trabalhos desenvolvem-se cobrindo desde a ultra-estrutura celular até $o$ aconselhamento genético, passando pelos vários aspectos de expressäio gênica, polimorfismos genéticos, cromossômicos e bioquímicos e evolução de organismos. As linhas de pesquisa cobrem assuntos desde a área básica até a aplicada, empregando técnicas clássicas e moleculares da Genética.

- Departamento de Botânica:

O Departamento de Botânica desenvolve pesquisas relacionadas com as quatro grandes subáreas dessa Ciência: anatomia vegetal; fisiologia vegetal; taxonomia, biologia e recursos econômicos de criptógamas e taxonomia, biologia e recursos econômicos de fanerógamas. As subáreas de anatomia, com quatro docentes, desenvolve suas atividades no laboratório de anatomia; especialmente com as seguintes linhas de pesquisa: anatomia fisiológica; anatomia ecológica; anatomia aplicada à taxonomia e filogenia; anatomia comparada e anatomia aplicada. A subárea de fisiologia, com cinco docentes, desenvolve suas atividades no laboratório de biologia celular de plantas, especialmente com as linhas de pesquisa em fisiologia do desenvolvimento com ênfase em cultura de tecidos e biologia molecular de plantas. A subárea de taxonomia, biologia e recursos econômicos de criptógamas, com cinco docentes, desenvolve suas atividades no laboratório de ficologia, em especial em linhas de pesquisa em taxonomia, biologia, fisiologia, citologia e biologia molecular de algas marinhas bentônicas, principalmente as de interesse econômico. A subárea de taxonomia, biologia e recursos econômicos de fanerógamas desenvolve suas atividades em dois laboratórios: o de Fitoquímica, que conta com três docentes e desenvolve linhas de pesquisa em quimiotaxonomia, ecologia química e fitoquímica, e o de sistemática, também com três professores, desenvolvendo pesquisas: em taxonomia e levantamentos florísticos na Cadeia do Espinhaço (MG, BA), taxonomia de gêneros e famílias brasileiras, flora de São Paulo.

- Departamento de Ecologia Geral 
O Departamento de Ecologia Geral realiza pesquisa em ecossistemas terrestres e aquáticos, utilizando diferentes abordagens. Os ecossistemas terrestres são abordados através do estudo da estrutura das comunidades e da dinâmica de populaçóes, do funcionamento enfocando a ciclagem de nutrientes minerais e da fisioecologia de fatores de tensão. Os aquáticos englobam os continentais de superfície e marinhos litorâneos. Realiza-se também macrolevantamento ambiental através de sensoriamento remoto, em ambos os ambientes, naturais ou alterados pelo homem. Realiza ainda pesquisas em ecoetologia de animais sociais e em ecologia evolutiva.

\section{- Departamento de Fisiologia Geral}

As pesquisas realizadas neste departamento referem-se a: respiração e metabolismo, estudando os mecanismos de tomada, transporte e utilizaçáo de oxigênio e remoção de gás carbônico, bem como os de catabolismo anaeróbico; osmorregulação, analisando os efeitos de estresse osmótico e iônico sobre organismos terrestres e aquáticos, considerando alteraçóes de volume celular e/ou elétricas de membranas; fisiologia da célula pigmentar, analisando a regulação hormonal da célula pigmentar de vertebrados e invertebrados, com ênfase nos mecanismos de transdução do sinal; comunicação química, analisando efeitos fisiológicos e de princípios naturais produzidos por organismos marinhos em várias preparaçóes farmacológicas; endocrinologia comparativa, analisando a regulação hormonal, em nível organísmico, de processos reprodutivos e metabólicos em peixes teleósteos; neurociências, estudando os processos neurais subjacentes à memória e aprendizagem em mamíferos; fisioecologia, estudando as adaptaçôes fisiológicas, oscilaçóes e estresse ambientais em organismos aquáticos e de transição água/terra.

\section{- Departamento de Zoologia}

As pesquisas desenvolvidas no Departamento de Zoologia, por docentes, pós-graduandos e estagiários, estão voltadas ao estudo da biologia, morfologia, anatomia funcional, comportamento, sistemática e evolução de invertebrados (Cnidaria, Mollusca, Annelida, Sipuncula, Echiura, Priapulida, Crustacea, Arachnida e Insecta) e vertebrados (peixes, anfíbios, répteis e aves) de água doce, marinhos e terrestres, especialmente da América do Sul. Além disso, realiza-se o estudo da composição faunística de comunidades zooplanctônicas de água doce e marinhas, de cavernas, de praias arenosas, de costóes rochosos e de outros ambientes.

Francisco Gorgonio Nóbrega é professor do Departamento de Biologia do Instituto de Biociências da USP. 